\title{
Media web-sites environmental communication: Operational practices and news coverage
}

\section{Nikos Antonopoulos}

Department of Digital Media and Communication, Ionian University, Greece

Minos-Athanasios Karyotakis ${ }^{1}$

School of Communication, Hong Kong Baptist University, Hong Kong

Matina Kiourexidou

Medical School, Aristotle University of Thessaloniki, Greece

Andreas Veglis

School of Journalism and Mass Communications, Aristotle University of Thessaloniki, Greece

DOI: 10.30547/worldofmedia.2.2019.3

\begin{abstract}
In contemporary world, it is estimated that there are 1,838,596,056 sites across $214,036,874$ unique domain names and 7,290,968 web-facing computers. The huge power consumption of these online services has serious consequences regarding the environment. The web-sites, along with the web tools, need electrical power to operate. Thus, environmental problems such as global warming, air pollution, natural resource depletion, and acid rain are worsening. Consequently, this study researched five hundred news web-sites including well-known international news organizations in order to understand if they choose to cover environmental news, if they take action to protect the Earth's habitat by operating through renewable sources, by using the black colour in their graphic design or energy saving mode, and by organizing actions in favour of the environment. The findings of this original research revealed that almost none of the prominent news web-sites of the world seem to care about changing their web-sites in order to become environmentally friendly.
\end{abstract}

\section{Keywords}

Environmental news, web-sites, global warming, online journalism.

\section{Corresponding author:}

Minos-Athanasios Karyotakis, School of Communication, Hong Kong Baptist University, Communication and Visual Arts Building 5, Hereford Road, Kowloon Tong, Kowloon, Hong Kong.

Email: minosathkar@yahoo.gr 


\section{Introduction}

\section{The field of environmental communication}

Environmental communication is a new field of study which includes the spread of environmental information and the communication of different agents, policies, and practices regarding environmental issues. From its creation it was related mostly to Environmentalism, and, as a result, it was a limited field of research. Nevertheless, throughout the years there has been a significant transformation as it started to include a far broader spectrum of agents (e.g. states, companies, transnational organizations, citizens, etc.) and communities which were having a positive or negative impact on the environment. This interaction between the aforementioned agents and the environment was also influenced by the cultural and news media products (Flor, 2004; Pezzullo \& Cox, 2018).

Web-sites have become a common tool for promotion, reading articles, etc. As a result, people think that it is a 'green' medium because of the simple fact that it often replaces paper. However, that is not the case (Frick, 2016). The web-sites often have countless pages to load in order to allow the user to navigate. Moreover, if the page has smaller files, then the server does not need to load unnecessary data on the page - such as photos and videos (Frick, 2016). These small energy savings accumulate over time and the goal of all should be to use less energy and lower carbon footprint. The servers that store the files that make up the web pages require power 24 hours a day so if we want a more sustainable web-site, the server hosting provider should operate with $100 \%$ renewable energy. Unfortunately, few amounts of power come from clean or renewable resources (Frick, 2016).

Therefore, environmental communication has become a more complex process due to the plethora of communication forms such as personal or interpersonal, verbal or non-verbal and visual, etc. Furthermore, during the last years phenomena such as the acid rain, global warming, climate change and others have provoked new communication actions that aim at promoting solutions to the current important environmental issues. Actually, everyone that actively promotes environmental concerns or solutions is participating in the process of environmental communication. Thus, countries have changed their policies so as to alter their citizens' environmental consciousness. This goal is linked with the ideas and opinions that are being passed down from one generation to the other. These are some of the reasons why this study tried to identify the way the news web-sites of international news organizations take part in environmental communication (Pezzullo \& Cox, 2018).

Environmental communication seems to be a field that began during the 1980s in the United States of America and it was associated with the rhetorical 
theory. The first scholars of the field via rhetorical methods explored the formed groups that were trying to protect the natural habitat along with the endangered animals and plants. Researchers had as an ultimate goal to attract public attention and inform it in favour of the environment. According to a broad consensus of scholars, Christine Oravec conducted the first research of the environmental communication discipline. The study about Yosemite Valley was published in 1981 and raised environmental awareness. The aforementioned study became also a starting point for other researchers to investigate more closely the impact of media organizations and products as well as the environmental consequences derived from humanity (Milstein, 2009).

In addition, cases such as the Chernobyl nuclear disaster in 1986 resulted in paying more attention to the regulations, the policies, and the communication strategies of dealing with the impact of environmental disasters and events. Additionally, the interpretation of the media products as a part of the field of journalism and mass communications led also to exploring the beliefs of the citizens towards the environment. Nowadays, the field of environmental communication is perceived as a crucial part of communication studies (Milstein, 2009). Thus, there is a specific division with the same name in the International Communication Association (https://www.icahdq.org/group/envirocomm). Moreover, in 2011, the International Environmental Communication Association was established (https://theieca.org/).

Additionally, unions of countries decided also to take action in favour of the environment. A prominent initiative for the sake of the environment was the climate summit, which took place in Paris (12 December 2015). According to Parker and Karlsson (2018): 'At the COP21 climate summit in Paris, 196 parties to the United Nations Framework Convention on Climate Change (UNFCCC) adopted an historic climate accord, the Paris Agreement. The Agreement aims to hold global warming to "well below" $2^{\circ} \mathrm{C}$ above pre industrial levels and to pursue "efforts to limit" it to $1.5^{\circ} \mathrm{C}$. The negotiations succeeded in bringing together long-divided protagonists from the developing and developed world in support of a new climate deal'. Despite the importance of this accord for the environment and the future of the planet, the new administration of the United States of America (USA) decided that the agreement cannot accomplish its goal. As a result, the President of the USA in the beginning of summer 2017 announced that the USA will no longer be a member of the agreement (Parker \& Karlsson, 2018).

Two years ago the European Union via the European Commission had issued the so-called 'Climate Adaptation Surgery', which was supposed to aim at changing the way European countries act regarding the environment (European 
Commission, 2016). It is worth mentioning that it is taken as an initiative from the European Union and not individually from a member-state. Thus, it was one of the first steps of the EU in changing the environmental behaviour of the memberstates at a more concrete level. Additionally, the policies like the aforementioned one, that is promoting the adaptation of the states towards the environment is somewhat a new notion. Nevertheless, all the policies are inseparably linked with the wills of the influential political actors, changing in the long run not only the resources but also the way that authority is being distributed (Remling, 2018). Finally, in the 2030 Agenda for Sustainable Development of the General Assembly of the United Nations around seven Sustainable Development Goals aim to protect the environment (United Nations, 2019).

Sustainability is an example of thinking about a future in which environmental, social and economic parameters are based on pursuing growth and improving the quality of life (UNESCO, 2012). There is a label from the European Union that promotes European environmental and ethical objectives (European Commission, 2019). On many web-sites it has been noticed that they have an icon for print friendly the article (Print friendly, 2019). The ISO 14020 series is designed to assist businesses with measuring and communicating their efforts to minimize their environmental impacts. Energy Star is a program with a primary goal of increasing energy efficiency and indirectly decreasing greenhouse gas emissions (Energy Star, 2019). A recent research showed also a combined Design for Environment and Life Cycle Assessment methodology for implementing eco-design in companies (Sanyé-Mengual et al., 2014). Hewlett Packard is working to reduce energy used in construction, to develop materials with less environmental impact and to design easily recyclable equipment (Hewlett-Packard, 2009).

Sustainable Development and the cope with the environmental problems have to have an international perspective for providing solutions not only in the economic field but also at an environmental level. This can happen by the managerial strategies of the companies and the technological environmental initiatives. In addition, there is a need for emphasizing on the importance of not causing any more damage to the environment in various ways (Petersen, 2007). Thus, media companies need also to participate in providing environmental solutions and to declare their environmental commitment. According to Henriques and Sadorsky (1999) companies have many ways of proving their environmental commitment:

'(1) having an environmental plan, (2) having a written document describing its environmental plan, (3) communicating its environmental plan to shareholders or stakeholders, (4) communicating this plan to employees, (5) 
having an environment, health, and safety (EHS) unit, and (6) having a board or management committee dedicated to dealing with environmental issues'.

Information and technology is an area that is related also to the field of environmental communication. Therefore, the news organisations have to pay more attention and be aware of the environmental problems that they cause. The next section focuses on this relation and its impact on the environment, as it has become more important in the last years due to the recent technological breakthroughs. That is one of the reasons why this study decided to focus on examining the operation of news web-sites, as this important topic seems not to have been researched from a communication perspective.

\section{Information technology and environmental communication}

New technologies are becoming an essential part of improving our everyday life, but in the meantime, they cause various environmental problems. The large consumption of online services has serious consequences regarding the environment. The web-sites along with the web tools need electrical power in order to operate. Thus, environmental problems such as global warming, air pollution, natural resource depletion, and acid rain are worsening. The main cause of global warming is climate change, which is mainly related to the greenhouse effect (Antonopoulos \& Veglis, 2013). Netcraft (2018) revealed that in the contemporary world there is an enormous number of web-sites. Specifically, it estimates that they are $1,838,596,056$ sites across $214,036,874$ unique domain names and 7,290,968 web-facing computers. Despite these services, mobile phones, smartphones, and other devices have created a new reality in relation to power consumption and greenhouse emissions. Environmental problems have led global political actors to take action (Parker \& Karlsson, 2018).

Internet services are contributing also to the climate change phenomenon. By consuming large sums of energy, they produce greenhouse gases (e.g. carbon dioxide). The finding of efficient solutions will provide humanity with a healthier habitat. As a result, the notion of 'green web-sites' has emerged. 'Green web-sites' are named the ones that use renewable sources of energy (Antonopoulos \& Veglis, 2012) and follow climate-friendly policies (Antonopoulos \& Veglis, 2013). This term came from the green colour, which is linked to nature and resembles the struggle in favour of the environment. Subsequently, the green parties around the globe use this specific colour in their logos. Overall, it is associated with computing, art, communication techniques, evangelicalism, etc. In addition, Internet services are dependent on Data centres, which are an essential part of the functioning of the World Wide Web. They offer the infrastructure for sheltering the Information Technology (IT) equipment and are responsible for 
security issues and the online and offline presence of a web page because Data centres store the web-sites' existed information. The Massachusetts Institute of Technology (MIT) tries to reduce the power consumption and the greenhouse gases of its university campus. Even not so prestigious Universities follow the example of MIT. For instance, in Greece, the biggest university of the country, Aristotle University of Thessaloniki (around 70,000 students) aims to use renewable energy as much as possible (Antonopoulos \& Veglis, 2013).

One of the main goals of Green Computing is to improve computing performance and reduce energy consumption and carbon footprints. The term green web-site refers to web-sites that are environmentally friendly aiming to environmentally sustainable computing. According to Murugesan (2008), the Green IT includes: design for environmental sustainability, energy-efficient computing, power management, data centre design, layout, and location, server virtualization, responsible disposal and recycling, regulatory compliance, green metrics, assessment tools, and methodology, environment-related risk mitigation, use of renewable energy sources and eco-labelling of IT products.

Taking into consideration these challenges, there were also the last years' actions that were derived from individuals, who wanted to promote and support environmentally friendly practices. The citizens' actions were linked with several green concepts. For instance, there were initiatives that had as fundamental values the element of innovation, the socio-environmental ethics, the anticonsumption perspective, etc. (Zapata Campos \& Zapata, 2017). Today, the spread of participation seemed to be easier than before, as the digitization of the current world provided far more ways of communicating with each other. In addition, the daily use of social media made the scholars pay closer attention to these changes as they seemed to have a significant impact on society (Skoric \& Poor, 2013).

This can be seen also to environmental actions. Green events around the world are being held to raise awareness about global warming. World Wide Fund for Nature's (WWF) earth hour is an environmental awareness movement that is related also to energy consumption and information technology (Earthhour. com, 2018). Anyone who wants to turn off the lights for an hour can participate in the Earth Hour. For 2019, the 30th of March 8:30 pm will be the day of the Earth Hour. During this day, many web-sites such as WWF, zara.com (Figure 1 and Figure 2), HM.com (Figure 3) include this environmental initiative on their online presence. According to the report named 'Earth Hour 2018 Highlights: Connect2Earth' (2018): 'Close to 18,000 landmarks switched off their lights in solidarity with the planet as people across the globe generated over 3.5 billion impressions of \#EarthHour, \#connect2earth and related hashtags to show their concern for the planet. The hashtags trended in 33 countries'. 
A post on the Facebook page of Zara Company regarding Earth Hour

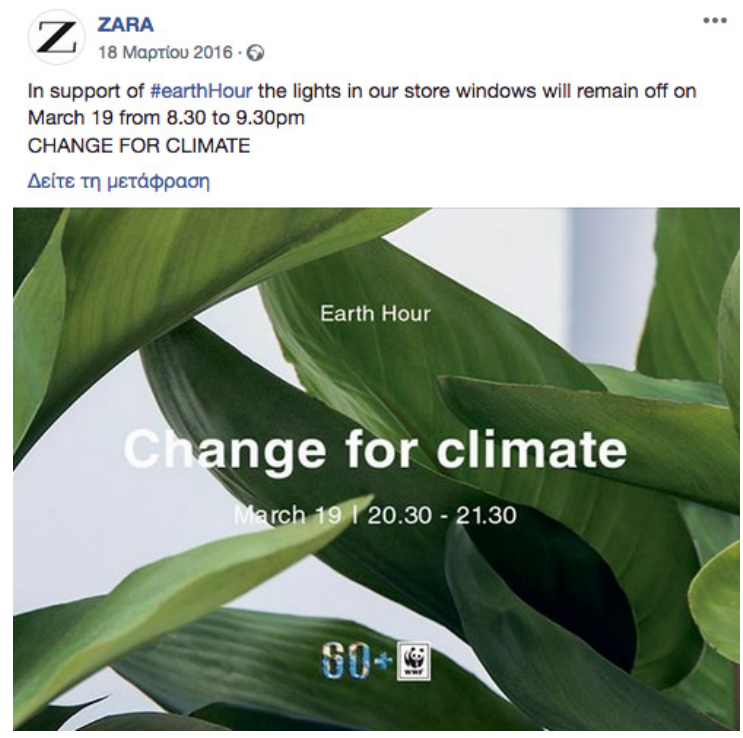

Figure 2

A tweet on the Twitter of Zara Company for the Earth Hour

$$
7 \text { ZARA }
$$

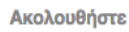

In support of \#EarthHour the lights in our store windows will remain off on March 29 from 8.30-9.30pm \#yourpower

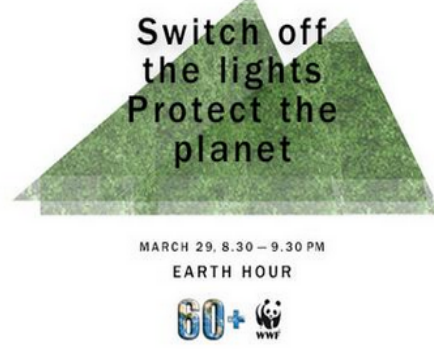




\section{A post on the Facebook page of H\&M for the Earth Hour}

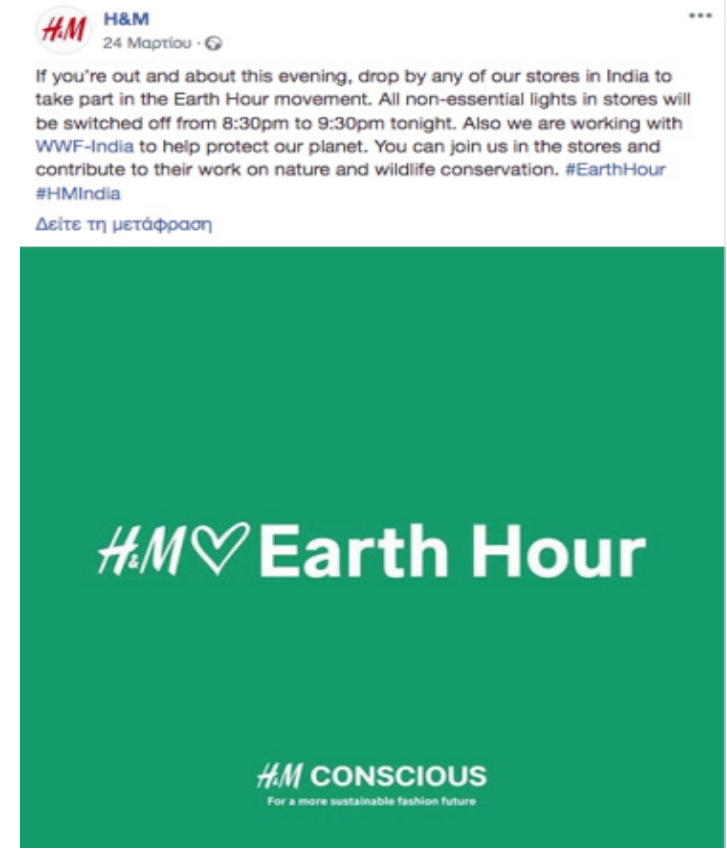

Environmental issues also have an impact on information technology. That is why this research aimed to study whether the web-sites are environmentally friendly and fill the gap in the current literature. The method is based on experiential observation and comparison with the listing of the data by the researchers. This topic has not been covered by a communication perspective until today. This original study researched 500 news web-sites including well-known international news organizations in order to see if they choose to cover environmental news as to influence the public in favour of the environment. Moreover, it is demonstrated if they take actions to protect the Earth's habitat by operating through renewable sources, using the black colour in their graphic design or energy saving mode, etc. Overall, this paper aimed to investigate the notion of 'green web-sites' in the current news media world.

\section{Methodology}

During the last few years, climate change has become an important issue for public discourse. Therefore, the researches regarding environmental 
communication have been advanced. Conducted surveys around the globe proved that the citizens recognize the need for taking action (Hansen, 2015; Swaffield \& Bell, 2012). Moreover, global climate change has provoked more than US\$200 billion in annual losses globally in relation to environmental catastrophes (Ho et al., 2015). When there are so many web-sites and so many environmental problems, the aim of the companies should be to have environmentally friendly web-sites, as it has been proven that green technologies have an important impact in favour of the environment (Spiller et al., 2017). In order to research this topic, based on the aforementioned two sections, a lot of parameters needed to be taken into consideration such as (a) if the news websites have a special category for environmental news, (b) if they are powered by renewable sources, (c) if they use the black colour in their graphic design, (d) if they provide the option to the user to transform the colour of the website into black, and (e) if the server that hosts the web-site is environmentally friendly.

The researchers visited all the web-sites of the sample and through observation and searching collected the empirical evidence. The research is based on experiential observation and comparison with listing of the data by the researchers, without being registered at the web-sites. The browsers that were employed were Google Chrome and Firefox. The scale of evaluation in every question was limited into two choices, presence (Yes) or absence (No). This is a case study, which researched and evaluated 500 news web-sites based on the alexa.com (web traffic analysis company) ranking. The web-sites were taken from the 'news' category (https://www.alexa.com/topsites/category/ Top/News), as according to Bolin and Hamilton (2018): 'Climate change presents a substantial challenge for science communication. News media play a central role that can either be constructive, exposing their audience to different perspectives and evidence-based information, or manipulative and divisive'.

The evaluation took place from the 30th of April 2018 to the 15th of May 2018. Some limitations have been made to secure that the sample will be homogenized. The evaluated web-sites needed to have an English version to be included in the assessment process, so that the researchers could read the information on the web-sites and provide the appropriate evidence for the evaluation. Additionally, the web-sites needed to offer free access, so as the user to have the opportunity of navigating on the web page without the obligation of registering. During the research, also the servers needed to be examined. Thus, the web-sites had to write on the first page or on the so-called pages 'about', 'privacy', 'terms', etc. that they are environmentally friendly and use renewable 
energy sources. Moreover, it was thought that it is important to investigate if the user has the capability of changing the background colour of a video to black for reducing the power consumption. As far as the research for environmentally friendly actions is concerned, they should have been organized by the examined medium rather than quoting/sharing them from other organizers. Lastly, in the news web-sites there are plug-ins that can understand if a user is active or not (mouse movement) in order to activate a screensaver (dark screen), which saves the consumed energy by turning off animations and other energy demanding operations of the web-site.

Specifically, the first research question is related to news coverage. It examined if the news media web-sites have a specific category for environmental issues because Carmichael and Brulle (2017) discovered that 'the greater the quantity of media coverage of climate change, the greater the level of public concern'. The second research question investigated if news web-sites are powered by renewable sources. Success in using renewable sources is believed to improve the environmental conditions by reducing the carbon emissions, widening the access to electricity and leading to larger financing of 'greener' technology (Bhattacharya et al., 2015). Moreover, it was examined whether the news websites use the black colour in their graphic design or if they provide the option to the user to transform the colour of the web-site into black (Antonopoulos \& Veglis, 2013).

It is a fact that black colour can lower the power consumption of a web-site. By knowing this, there was also an investigation in relation to the inactivity of the user and the energy saving mode. Specifically, there are plug-ins that can understand if a user is active or not. Therefore, if the user is inactive then a dark screen emerges in order to turn on the energy saving mode that deactivates simultaneously some animations and operations of the web-site to reduce the power consumption (Antonopoulos \& Veglis, 2013).

These kinds of processes are related to the interactivity of the web-site, which is defined as 'the state or process of communicating, exchanging obtaining and/ or modifying content (e.g., ideas, entertainment, product information) and/ or its form with or through a medium (e.g., computer, modem, etc.) which responds to both the communicator's and the audience's communication needs by including hypertext links, reciprocal communication and so on' (Míguez-González \& Fernández-Cavia, 2015). Finally, the behaviour of the news organizations in association with their participation in environmental events or actions to protect the environment was examined, as these kinds of actions can affect significantly national environmental beliefs (Dalton, 2015). 
Hence, the following five research questions were asked (Antonopoulos \& Veglis, 2013; Frick, 2016):

RQ1. Do the examined news web-sites have an environment category?

RQ2. Is the server of the web-site environmentally friendly?

RQ3. Is the user allowed to change the background colour into black when he/she is watching videos?

RQ4. Do the examined web-sites, in the event of user inactivity, have a screensaver?

RQ5. Has the examined media company that owns the web-site ever organized actions in favour of the environment?

\section{Results}

Two of the 500 web-sites were not examined for this scientific paper, as they did not have an English version. Apart from these facts, a news web portal was not working, and there were two of them with the same Uniform Resource Locator (URL). As a result, in all the research questions of the study there is a one percent error ( $1 \%$ error), which is due to these five cases. More specifically, the first case is the ranking number 117 (bbc.co.uk/news/business) because it is the same with number 7 (bbc.co.uk). The second case is the ranking number 190 (nj.com/news) because it is the same with number 76 (nj.com). The third and fourth errors were the media web-sites with ranking number 235 (spiegel.de). Finally, the web-site number 420 (andhrabhoomi.net) did not have an English version and the web-site Bendbulletin.com with ranking number 479 was not accessible.

Regarding the first question, the evaluation revealed 128 'Yes' (26\%), 367 'No' (73\%), and 5 (1\%) 'Error'. It is noteworthy the fact that they used different words in the menu such as Environment, Climate, Earth, Energy, and others. On the Today.duke.edu there was no headline on the main menu or on the first page for environmental news, but via a search within the content of the web-site, it was discovered that there were 4,869 tags with the word 'Environment'. On the Telegraphjournal.com, the user could only navigate by signing up. Therefore, the research questions $2,3,4$, and 5 were explored and evaluated depending on the pages, which were free and open for navigation (Figure 4). 
Figure 4

The percentage out of the 500 web-sites that have a specific category for environmental issues/news

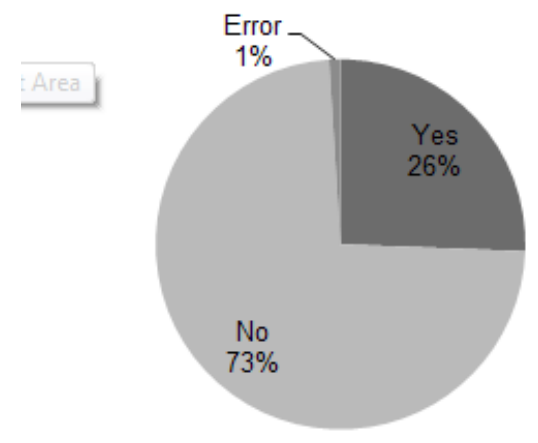

The percentage of the 'Yes' answers for the second research question was zero (0\%). The 'No' answer was 495 (99\%) in total, excluding again the five web-sites that are counted as an error. However, there were also four other websites that did not include any information on their page about their server. In order to provide a proper answer to this query, a search was conducted on the World Wide Web for the following web-sites: News.google.com, News.yahoo. com, My.yahoo.com, and Metafilter.com. The final outcome was that the aforementioned services use environmentally friendly servers, as there was this text on their page: 'The site is currently being served by Amazon Web Services' (Figure 5).

Figure 5

The percentage out of the 500 web-sites that have an environmentally friendly server

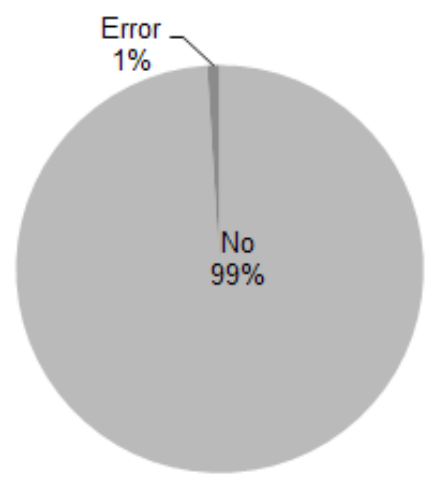


For the third question of the survey, in 457 (91\%) web-sites the user was not allowed to change the background colour into black when he/she was watching videos. There were only 38 (8\%) web-sites that were offering the feature of the black background colour. However, 31 web-sites had a permanent black background in the videos and 5 became black in a pop-up window when the user was watching videos. Consequently, only two were the web-sites that were actually offering the user the chance to change the background colour into the black during a video (Figure 6).

Figure 6

\section{The user is allowed to change the background colour when they are watching videos}

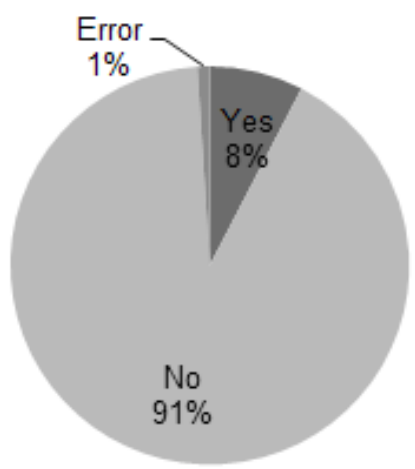

For the fourth question of the survey, the positive answers for the existence of a screen saver were zero (0\%). Therefore, all the answers 495 (99\%) were negative. As far as the last research question is concerned, only $29(6 \%)$ of the web-sites had taken initiatives and organized actions in favour of the environment. On the contrary, the majority of them, 466 (93\%), had not created an environmentally friendly event. It is impressive though that from the 13 websites, which were created by university departments, almost all of them (11) had organized environmental events (Figure 7). 
The examined web-sites, which in the case of user's inactivity have a screensaver (A), and the web-sites that have organized actions in favour of the environment (B)
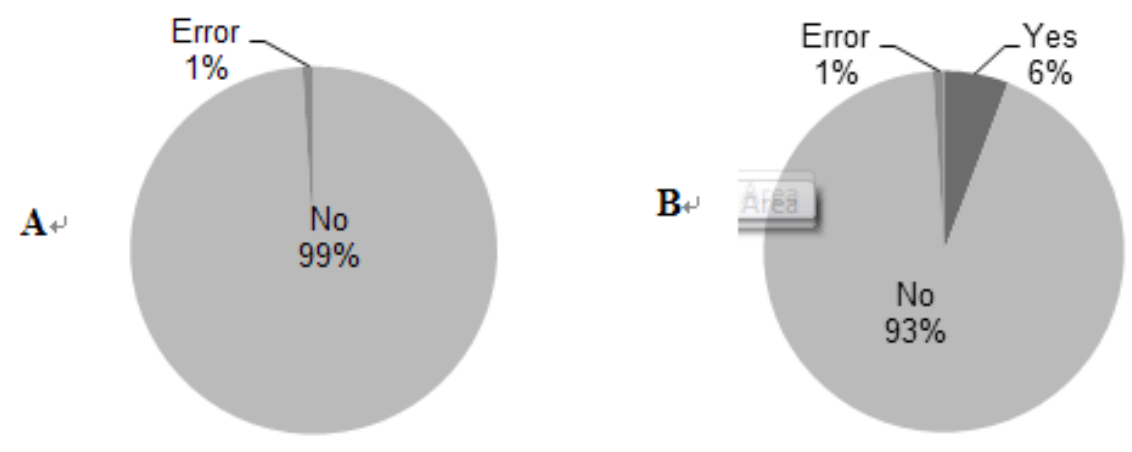

Finally, it should be mentioned that the current study examined some of the most prominent web-sites of international news organisations in the world. For instance, the sample included web-sites such as The Guardian (United Kingdom), The Hindu (India), The New York Times (United States of America), Al Jazeera (Qatar), China Daily (People's Republic of China), Fox News (United States of America), etc.

\section{Discussion}

News organizations and news stories are important for shaping the opinion of the public, as they can influence people by focusing on specific incidents in order to promote their narratives. Fox News has affected public discourse regarding climate change in a certain direction (Bolin \& Hamilton, 2018). Moreover, Carmichael and Brulle (2017) proved that there is a strong correlation amongst the environmental news and the public because the public concern is proportional to news coverage. Subsequently, it is significant for news outlets to have a special category for environmental news. However, this research (Figure 8) demonstrated that the majority of the examined news organizations do not have a special section for environmental news. From the sample of 500 websites, only the 128 had a unique category for environmental news, demonstrating that environmental news does not seem to be essential for them (RQ1).

As far as the second research question of this study is concerned (RQ2), almost none of the web-sites use environmentally friendly servers (Antonopoulos \& Veglis, 2012). After an extensive search, it was found that only four web portals (News.google.com, News.yahoo.com, My.yahoo.com, and Metafilter.com), are 
using environmentally friendly servers (Amazon Web Services). Consequently, it was demonstrated that the most prominent web-sites of the world do not take into serious consideration the consequences that the online services have for the environment. The use of renewable sources is critical, as they are believed to improve the environmental conditions by reducing the carbon emissions, widening the access to electricity and leading to larger financing of 'greener' technology (Bhattacharya et al., 2015).

The third research question of the study (RQ3) revealed that there is also a major problem with the use of the black colour in the graphic design when users are watching videos. Again, almost none of the web-sites used the black colour (91\%). From the 38 (8\%) with the background colour only two were the ones that provided the option of altering the colour of the web-site to black. Meanwhile, all the examined web-sites did not even have screensavers in case there was an inactive user (RQ4). According to Veglis and Antonopoulos (2013), black colour can reduce the power consumption of a web-site. Additionally, there are plug-ins that can understand if a user is active or not in order to activate a screensaver (dark screen), which saves the consumed energy by turning off animations and other energy demanding operations of the web-site.

Figure 8

The overall results of the research

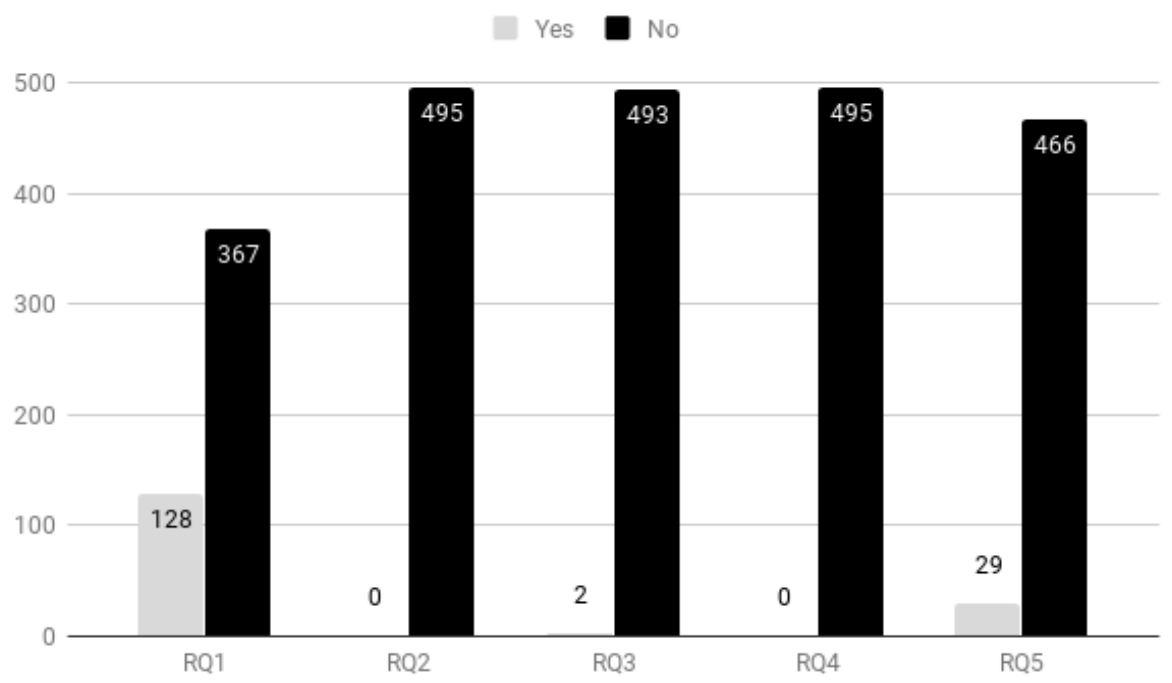

Nevertheless, the fifth research question (RQ5) of this study proved that, at least, some of the web-sites had organized events and actions to protect the 
environment (6\%). The majority of these web-sites (11 out of 13 ) were created by universities, which indicated that universities as creators of web portals can play a crucial role in promoting or holding environmental events. This finding seems to differ from the will of the citizens towards the environment, as during the last years, individuals throughout the world have recognized the need to act and protect the natural habitat (Swaffield \& Bell, 2012). Therefore, initiatives such as the fossil fuel divestment (FFD) movement have emerged (Mangat et al., 2018).

\section{Conclusion}

The operation of the news web-sites in relation to the environment has not been examined extensively until today. World Wide Web services have become numerous. Subsequently, their operation should be taken into consideration if the globe wants to protect the environment, as they produce also greenhouse emissions. The notion of 'green web-sites' is associated with the climate-friendly policies and aims to improve the natural habitat of Earth. Renewable sources, the use of black colour, and the highlight of the environmental news are some of the easiest and cheapest ways to contribute positively to climate issues. However, even the most prominent international news organizations of the world do not seem to take into serious consideration their role regarding environmental issues. Thus, the majority of them do not focus on such stories. Furthermore, they do not try to operate via renewable sources or just to try to reduce their power consumption. Overall, almost none of the popular news web-sites of the world seem to care about changing their web-sites in order to become environmentally friendly.

At this point, it should be mentioned that this study examined only the top web-sites of the world according to the 'news' category of alexa.com. Another study that is based on a different traffic web-site company might provide different results. Finally, future studies can focus more on other web-sites categories in order to investigate if the above-mentioned findings represent the overall situation of the web-sites' operation around the world.

\section{Declaration of interest statement}

No potential conflict of interest was reported by the authors.

\section{References}

ANTONOPOULOS, N. \& VEGLIS, A. (2012). Technological characteristics and tools for web media companies in Greece. In: D. D. Vergados \& C. Lambrinoudakis, Proceedings of the 16th Panhellenic Conference on Informatics. Piraeus, IEEE Computer Society, pp. 44-49. 
ANTONOPOULOS, N. \& VEGLIS, A. (2013). Web media techniques and tools for green communication practices. In: B. Leon, Proceedings of the COMXVIII International Conference of Communication. Navara, pp. 17-43.

BHATTACHARYA, M., PARAMATI, S. R., OZTURK, I., \& BHATTACHARYA, S. (2015). The effect of renewable energy consumption on economic growth: Evidence from top 38 countries. Applied Energy, 162, pp. 733-741.

BOLIN, J. L. \& HAMILTON, L. C. (2018). The news you choose: News media preferences amplify views on climate change. Environmental Politics, 27(3), pp. 455-476.

DALTON, R. J. (2015). Waxing or waning? The changing patterns of environmental activism. Environmental Politics, 24(4), pp. 530-552.

Earthhour.com. (2018). Earth Hour. Available from: https://www.earthhour. org

Energy Star. (2019). About Energy Star. Available from: https://www. energystar.gov/about

European Commission (2019). Environment. Available from: http:// ec.europa.eu/environment/ecolabel

European Commission (2016). EU adaptation strategy. Available from: https://ec.europa.eu/clima/policies/adaptation/what_en

FLOR, G. A. (2004). Environmental communication: Principles, approaches, and strategies of communication applied to environmental management. Diliman, Quezon City, University of the Philippines, Open University.

FRICK, T. (2016). Designing for sustainability: A guide to building greener digital products and services. USA, O' Reilly Media.

HANSEN, A. (2015). Promising directions for environmental communication research. Environmental Communication, 9(3), pp. 384-391.

HENRIQUES, I. \& SADORSKY, P. (1999). The relationship between environmental commitment and managerial perceptions of stakeholder importance. Academy of Management Journal, 42(1), pp. 87-99.

Hewlett-Packard (2009). Designing for the environment. Available from: http://www.hp.com/hpinfo/newsroom/press_kits/2009/ecosolutions/ reduceimpact/PSGEcoPressFactSheet.pdf

HO, S. S., LIAO, Y., \& ROSENTHAL, S. (2015). Applying the theory of planned behavior and media dependency theory: Predictors of public proenvironmental behavioral intentions in Singapore. Environmental Communication, 9(1), pp. 77-99.

JASON, T., CARMICHAEL, J. T., \& BRULLE, R. J. (2017). Elite cues, media coverage, and public concern: An integrated path analysis of public opinion on climate change, 2001-2013. Environmental Politics, 26(2), pp. 232-252. 
MANGAT, R., DALBY, S., \& PATERSON, M. (2018). Divestment discourse: War, justice, morality and money. Environmental Politics, 27(2), pp. 187-208.

MÍGUEZ-GONZÁLEZ, M. I. \& FERNÁNDEZ-CAVIA, J. (2015). Tourism and online communication: Interactivity and social web in official destination websites. Communication \& Society, 28(4), pp. 17-31.

MILSTEIN, T. (2009). Environmental communication theories. In: S. W. Littlejohn \& A. F. Karen, Encyclopedia of communication theory. Thousand Oaks, SAGE Publications Inc., Vol. 1-2, pp. 345-349.

MURUGESAN, S. (2008). Harnessing green IT: Principles and practices. IT Professional, 10(1), pp. 24-33.

Netcraft (2018). Web server survey. Available from: https://news.netcraft. com/archives/category/web-server-survey

PARKER, C. F. \& KARLSSON, C. (2018). The UN climate change negotiations and the role of the United States: Assessing American leadership from Copenhagen to Paris. Environmental Politics, 27(3), pp. 519-540.

PETERSEN, L. K. (2007). Changing public discourse on the environment: Danish media coverage of the Rio and Johannesburg UN summits. Environmental Politics, 16(2), pp. 206-230.

PEZZULLO, P. C. \& COX, R. (2018). Environmental communication and the public sphere. Indiana University, USA, SAGE Publications, Inc.

Print friendly (2019). Make any web-page - Print Friendly \& PDF. Available from: https://www.printfriendly.com

REMLING, E. (2018). Depoliticizing adaptation: A critical analysis of EU climate adaptation policy. Environmental Politics, 27(3), pp. 477-497.

SANYÉ-MENGUAL, E., LOZANO, R. G., FARRENY, R., RIERADEVALL, OLIVER-SOLA, J., GASOL, C., \& RIERADEVALL, J. (2014). Introduction to the eco-design methodology and the role of product carbon footprint. In: S. S. Muthu, Assessment of carbon footprint in different industrial sectors. Singapore, Springer Science+Business Media.

SKORIC, M. M. \& POOR, N. (2013). Youth engagement in Singapore: The interplay of social and traditional media. Journal of Broadcasting \& Electronic Media, 57(2), pp. 187-204.

SPILLER, E., SOPHER, P., MARTIN, N., MIRZATUNY, M., \& ZHANG, $X$. (2017). The environmental impacts of green technologies in TX. Energy Economics, 68, pp. 199-214.

SWAFFIELD, J. \& BELL, D. (2012). Can 'climate champions' save the planet? A critical reflection on neoliberal social change. Environmental Politics, 21(2), pp. 248-267.

UNESCO (2012). Education for sustainable development: Sourcebook. Available from: https://unesdoc.unesco.org/ark:/48223/pf0000216383 
United Nations (2019). Transforming our world: The 2030 agenda for sustainable development. Available from: https://sustainabledevelopment. un.org/content/documents/21252030\%20Agenda\%20for\%20Sustainable\% 20Development\%20web.pdf

World Wide Fund for Nature (2018). Earth Hour 2018 highlights: Connect2Earth. Available from: http://awsassets.panda.org/downloads/ earth_hour_2018_report.pdf

ZAPATA CAMPOS, M. J. \& ZAPATA, P. (2017). Infiltrating citizen-driven initiatives for sustainability. Environmental Politics, 26(6), pp. 1055-1078. 